Кириллина Юлия Владимировна

кандидат экономических наук, доцент, доцент кафедры практической и прикладной информатики

Московского технологического университета

\section{АНАЛИЗ РЕЗУЛЬТАТОВ МОНИТОРИНГА 2014 И МОНИТОРИНГА 2017}

\begin{abstract}
Аннотация:
В статье анализируются изменения в системе высшего образования г. Москвы и Московской области на основе результатов Мониторинга 2014 и Мониторинга 2017. Выбор двух названных регионов определен тем, что они являются крупнейшими по численности населения, объему рынка труда, а также количеству организаций высшего образования и числу студентов в Центральном федеральном округе. Для анализа были использованы статистические показатели мониторинга и вариации. В частности, речь идет о среднем значении, моде, медиане, коэффициенте вариации. Проведено сравнение критериев центра распределения и коэффициентов вариации за рассмотренный период, полученных по результатам обработки статистических сведений. Обосновывается достижение однородности в составе образовательных учреждений двух регионов.
\end{abstract}

Ключевые слова:

вузы, филиалы, мониторине эффективности, критерии эффективности, анализ, изменение, коэфффициент вариации.
Kirillina Yulia Vladimirovna

PhD in Economics, Associate Professor, Practical and Applied Computer Science Department

Moscow Technological University

\section{CONCERNING THE RESULTS OF HIGHER EDUCATION INSTITUTIONS EFFECTIVENESS MONITORING 2014 AND 2017}

Summary:

The study analyzes the changes in higher education system in Moscow and Moscow region according to the results of Higher Education Institutions Effectiveness Monitoring 2014 and 2017. The choice of the abovementioned territories is determined by the fact that they are the most populous regions with the largest labor markets and a great number of higher education institutions and students in Central Federal District. The analysis is based on statistical indicators of monitoring and variation, in particular, the mean, mode, median, and coefficient of variation. The paper compares the measures of central tendency with the coefficients of variation for the period under review. The author proves that the educational institutions in Moscow and Moscow region have the homogeneous structure.

Keywords:

higher education institutions, branches, monitoring of effectiveness, effectiveness measures, analysis, variation, coefficient of variation.

Мониторинг эфффективности деятельности образовательных организаций высшего образования (ВО) в России осуществляется в течение 5 лет. Первое исследование было проведено в 2013 г. на основе данных о деятельности вузов и филиалов за 2012 г. Именно на базе Мониторинга 2013 Межведомственной комиссией (МВК) приняты следующие исторические решения:

- оптимизация деятельности 26 головных образовательных организаций и 15 фрилиалов;

- реорганизация 79 вузов и 202 филиалов;

- отсутствие единой позиции МВК по 50 вузам и 31 филиалу;

- реализация иных действий в отношении 11 вузов и 5 филиалов;

- отнесение 31 вуза и 15 фрилиалов к группе «нуждающихся в оптимизации»;

- отнесение 135 вузов и 24 филиалов к группе «образовательная организация, являющаяся неэффективной и нуждающаяся в реорганизации» [1].

Для системы высшего образования 2013-2016 годы стали периодом реорганизаций, оптимизаций, приостановления и лишения свидетельств об аккредитации и лицензий на образовательную деятельность. За это время изменились и критерии мониторинга, и само высшее образование.

В качестве информационной базы для проводимого в статье анализа использованы данные Мониторинга 2014 и Мониторинга 2017 (представленные на сайте Главного информационно-аналитического центра Минобрнауки РФ) по двум субъектам РФ: г. Москве и Московской области [2]. Этот выбор обоснован тем, что Мониторинг 2014 г. представляет собой полноценный инсрормационно-аналитический материал по каждому субъекту РФ в отличие от Мониторинга 2013, где для получения сведений необходимо вводить полное наименование образовательной организации. Также неслучайно обращение к двум указанным субъектам РФ: г. Москва и Московская область являются крупнейшими территориями по численности населения, рынку труда, числу учреждений высшего образования и количеству студентов в Центральном федеральном округе.

В первую очередь необходимо отметить, что за 2013-2017 гг. изменились критерии, по которым оценивается эффективность деятельности вуза (таблицы 1, 2). Отсутствует показатель 
«Инфраструктура», самостоятельным стал критерий «Трудоустройство», появился фактор «Заработная плата ППС». Пороговые значения критериев «Образовательная деятельность», «Научно-исследовательская деятельность», «Финансово-экономическая деятельность» с момента проведения Мониторинга 2014 остались неизменными, что фактически послужило ориентиром в рамках формирования и реализации стратегии повышения эффективности деятельности для каждого вуза и филиала г. Москвы и Московской области.

Таблица 1 - Пороговые значения критериев эффективности Мониторинга 2014

\begin{tabular}{|c|c|c|c|c|c|c|c|}
\hline \multirow[b]{2}{*}{ Субъект РФ } & \multicolumn{7}{|c|}{ Критерий эффрективности и его значение } \\
\hline & 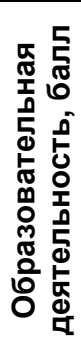 & 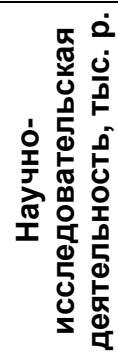 & 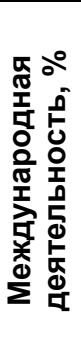 & 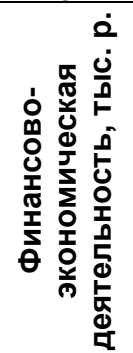 & 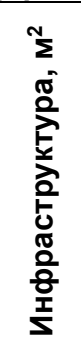 & 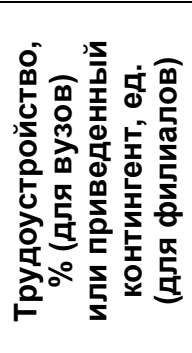 & 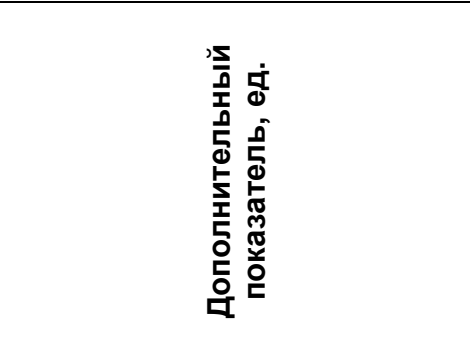 \\
\hline г. Москва & 64,5 & 136,37 & 4 & 2139,60 & 14,1 & $99,5 / 220$ & $\begin{array}{l}\text { Значение в зависимости от } \\
\text { наличия/отсутствия специфики } \\
\text { деятельности }\end{array}$ \\
\hline $\begin{array}{l}\text { Московская } \\
\text { область }\end{array}$ & 60,0 & 51,28 & 1 & 1327,57 & 13,9 & $98,5 / 220$ & $\begin{array}{l}\text { Значение в зависимости от } \\
\text { наличия/отсутствия специффики } \\
\text { деятельности }\end{array}$ \\
\hline
\end{tabular}

Таблица 2 - Пороговые значения критериев эффективности Мониторинга 2017

\begin{tabular}{|c|c|c|c|c|c|c|c|}
\hline \multirow[b]{2}{*}{ Субъект РФ } & \multicolumn{7}{|c|}{ Критерий эффективности и его значение } \\
\hline & 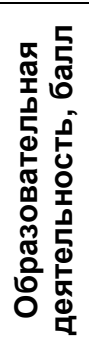 & 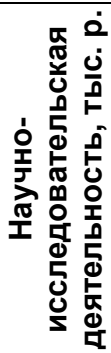 & 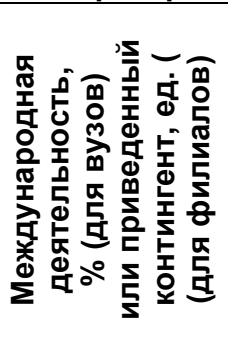 & 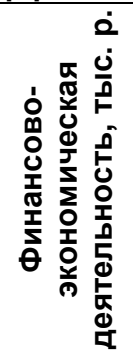 & 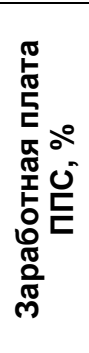 & 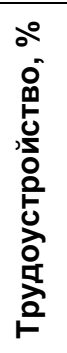 & 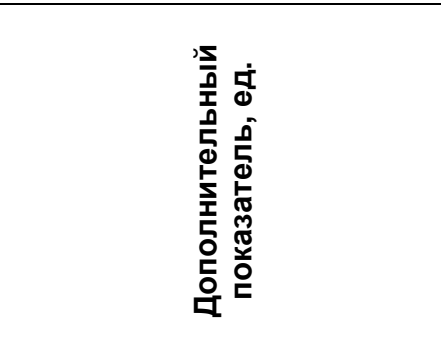 \\
\hline г. Москва & 64,5 & 136,37 & $4,02 / 220$ & 2139,60 & 150 & 65 & $\begin{array}{l}\text { Значение в зависимости от } \\
\text { наличия/отсутствия специ- } \\
\text { фики деятельности }\end{array}$ \\
\hline $\begin{array}{l}\text { Московская } \\
\text { область }\end{array}$ & 60,0 & 51,28 & $1,0 / 220$ & 1327,57 & 150 & 70 & $\begin{array}{l}\text { Значение в зависимости от } \\
\text { наличия/отсутствия специ- } \\
\text { фики деятельности }\end{array}$ \\
\hline
\end{tabular}

Статистические данные по учебным заведениям, участвующим в Мониторинге 2014 и Мониторинге 2017, приведены в таблицах 3 и 4. Количество образовательных учреждений ВО за 3 года в г. Москве снизилось на 38,7 \% за счет реорганизации, оптимизации, лишения лицензий на образовательную деятельность и свидетельств об аккредитации; в Московской области данный показатель составил 55,6 \%. В Подмосковье это коснулось в большей степени филиалов. Их число сократилось на 63,5%. В г. Москве количество вузов уменьшилось на 31,4 \%.

Таблица 3 - Образовательные учреждения ВО г. Москвы, ед.

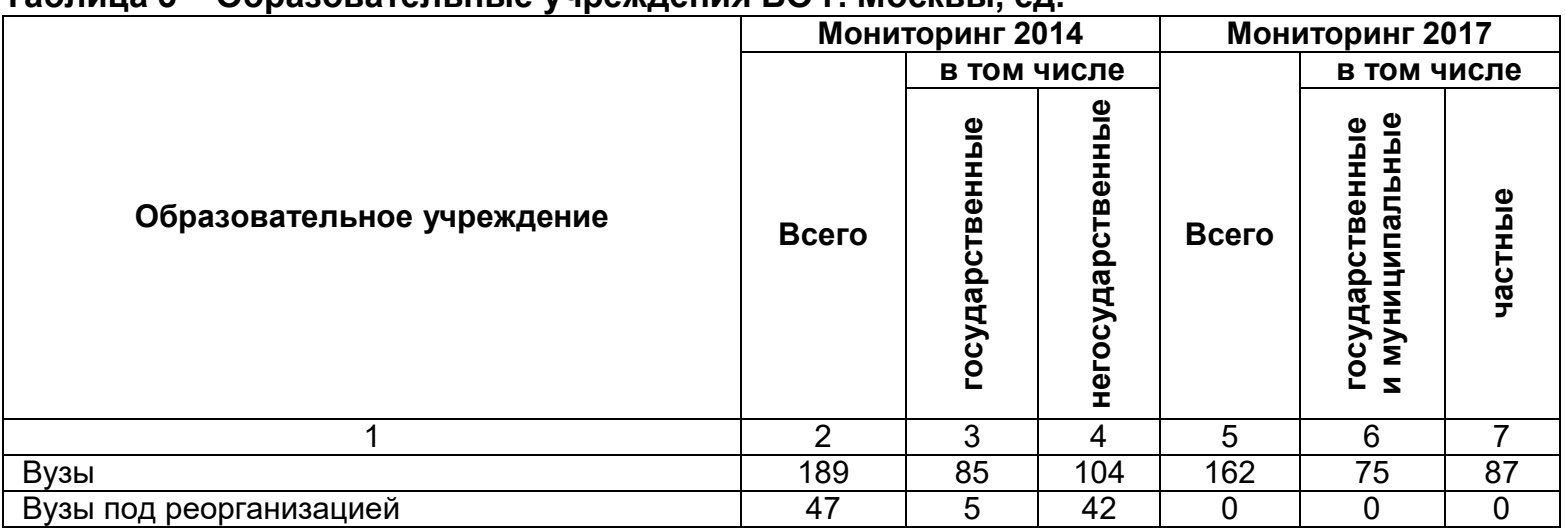


Продолжение таблицы 3

\begin{tabular}{|l|c|c|c|c|c|c|}
\hline \multicolumn{1}{|c|}{1} & 2 & 3 & 4 & 5 & 6 & 7 \\
\hline Итого вузов & 236 & 90 & 146 & 162 & 75 & 87 \\
\hline Филиалы & 6 & 3 & 3 & 5 & 3 & 2 \\
\hline Филиалы под реорганизацией & 1 & 1 & 0 & 0 & 0 & 0 \\
\hline Итого филиалов & 7 & 4 & 3 & 5 & 3 & 2 \\
\hline Итого образовательных учреждений & 243 & 94 & 149 & 167 & 78 & 89 \\
\hline
\end{tabular}

Таблица 4 - Образовательные учреждения ВО Московской области, ед.

\begin{tabular}{|c|c|c|c|c|c|c|}
\hline \multirow[b]{3}{*}{ Образовательное учреждение } & \multicolumn{3}{|c|}{ Мониторинг 2014} & \multicolumn{3}{|c|}{ Мониторинг 2017} \\
\hline & \multirow[t]{2}{*}{ Bcero } & \multicolumn{2}{|c|}{ в том числе } & \multirow[t]{2}{*}{ Всего } & \multicolumn{2}{|c|}{ в том числе } \\
\hline & & 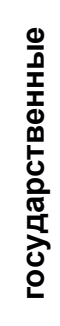 & 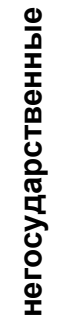 & & 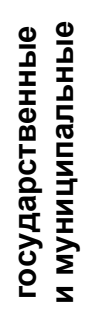 & $\begin{array}{l}\frac{0}{0} \\
\mathbf{1} \\
\frac{\mathbf{U}}{\sigma} \\
\frac{\mathbb{0}}{J}\end{array}$ \\
\hline Вузы & 33 & 16 & 17 & 25 & 12 & 13 \\
\hline Вузы под реорганизацией & 3 & 0 & 3 & 0 & 0 & 0 \\
\hline Итого вузов & 36 & 16 & 20 & 25 & 12 & 13 \\
\hline Филиалы & 82 & 47 & 35 & 41 & 27 & 14 \\
\hline Филиалы под реорганизацией & 33 & 12 & 21 & 1 & 1 & 0 \\
\hline Итого филиалов & 115 & 59 & 56 & 42 & 28 & 14 \\
\hline Итого образовательных учреждений & 151 & 75 & 76 & 67 & 39 & 28 \\
\hline
\end{tabular}

В 2014 г. при проведении исследования 54 образовательных организации г. Москвы либо не представили отчет, либо не передали его для обработки в бумажном виде, либо указанные ими данные были подвергнуты анализу достоверности. В 2017 г. уже 66 образовательных учреждений не представили отчет, что на 20 \% больше, чем в 2014 г. По Московской области в 2014 г. таких учебных заведений ВО было всего 4, в 2017 - 8, прирост значения показателя составил $100 \%$.

В таблицах 5 и 6 приведено распределение организаций ВО г. Москвы и Московской области по числу выполненных критериев по результатам Мониторинга 2014 и Мониторинга 2017. За 3-летний период наблюдается следующее изменение (без учета количества реорганизуемых учреждений и получивших отметку X):

- в 2013 г. по г. Москве наибольший удельный вес (18,1\%) занимали организации, выполнившие 4 критерия, в 2016 г. - 5 (27,0\%);

- по Московской области в 2013 г. 21,9 \% организаций выполнили 3 критерия, в 2016 г. 5 показателей реализовали уже $26,1 \%$ всех учреждений;

- в целом по двум субъектам РФ в 2013 г. преобладали организации, выполнившие 4 критерия, в 2016 г. $-5(26,1 \%)$.

Таблица 5 - Распределение учебных заведений ВО по количеству выполненных критериев по Мониторингу 2014

\begin{tabular}{|c|c|c|c|c|c|c|c|c|c|c|}
\hline \multirow[b]{2}{*}{$\begin{array}{c}\text { Образовательное } \\
\text { учреждение }\end{array}$} & \multicolumn{9}{|c|}{ Количество выполненных критериев / категория учреждения } & \multirow[b]{2}{*}{ Всего } \\
\hline & $\begin{array}{c}\text { Реорганизуемое } \\
\text { учреждение }\end{array}$ & 0 & 1 & 2 & 3 & 4 & 5 & 6 & 7 & \\
\hline $\begin{array}{l}\text { Учебные заведения } \\
\text { г. Москвы }\end{array}$ & 48 & 4 & 14 & 36 & 41 & 44 & 30 & 19 & 7 & 243 \\
\hline Итого, \% & 19,7 & 1,6 & 5,8 & 14,8 & 16,9 & 18,1 & 12,3 & 7,8 & 2,9 & 100 \\
\hline $\begin{array}{l}\text { Учебные заведения } \\
\text { Московской области }\end{array}$ & 36 & 3 & 5 & 19 & 33 & 27 & 13 & 10 & 5 & 151 \\
\hline Итого, \% & 23,8 & 2,0 & 3,3 & 12,6 & 21,9 & 17,9 & 8,6 & 6,6 & 3,3 & 100 \\
\hline $\begin{array}{l}\text { Итого по двум } \\
\text { субъектам РФ, ед. }\end{array}$ & 84 & 7 & 19 & 55 & 74 & 71 & 43 & 29 & 12 & 394 \\
\hline $\begin{array}{l}\text { Итого по двум } \\
\text { субъектам РФ, \% }\end{array}$ & 21,3 & 1,8 & 4,8 & 14 & 18,8 & 18 & 11 & 7,3 & 3,0 & 100 \\
\hline
\end{tabular}


Таблица 6 - Распределение учебных заведений ВО по количеству выполненных критериев по Мониторингу 2017

\begin{tabular}{|l|c|c|c|c|c|c|c|c|c|c|c|}
\hline \multirow{2}{*}{$\begin{array}{c}\text { Образовательное } \\
\text { учреждение }\end{array}$} & $\begin{array}{c}\text { Количество выполненных критериев / категория учреждения } \\
\text { учреждение }\end{array}$ & $\mathbf{0}$ & $\mathbf{1}$ & $\mathbf{2}$ & $\mathbf{3}$ & $\mathbf{4}$ & $\mathbf{5}$ & $\mathbf{6}$ & $\mathbf{7}$ & $\mathbf{X}$ & Всего \\
\hline $\begin{array}{l}\text { Учебные заведения } \\
\text { Г. Москвы }\end{array}$ & 0 & 0 & 0 & 5 & 5 & 25 & 45 & 21 & 15 & 51 & 167 \\
\hline Итого, \% & 0 & 0 & 0 & 3 & 3 & 15 & 27 & 13 & 9 & 31 & 100 \\
\hline $\begin{array}{l}\text { Учебные заведения } \\
\text { Московской области }\end{array}$ & 1 & 0 & 1 & 2 & 5 & 12 & 16 & 15 & 5 & 10 & 67 \\
\hline Итого, \% & 1 & 0 & 1 & 3 & 7 & 18 & 24 & 22 & 7 & 15 & 100 \\
\hline $\begin{array}{l}\text { Итого по двум } \\
\text { субъектам РФ, ед. }\end{array}$ & 1 & 0 & 1 & 7 & 10 & 37 & 61 & 36 & 20 & 61 & 234 \\
\hline $\begin{array}{l}\text { Итого по двум } \\
\text { субъектам РФ, \% }\end{array}$ & 0,4 & 0 & 0,4 & 3,0 & 4,3 & 15,8 & 26,1 & 15,4 & 8,5 & 26,1 & 100 \\
\hline
\end{tabular}

Необходимо отметить, что в Мониторинге 2017 знаком Х отмечены следующие вузы и фрилиалы:

- находящиеся в стадии реорганизации, по результатам Мониторинга 2016 не выполнили 4 показателя или более;

- имеющие по критерию «Трудоустройство» формулировку «Не предоставлены сведения в ФРДО».

Если учесть, что последнюю пометку получили ФГАОУ ВО «Национальный исследовательский технологический университет «МИСиС», ФГАОУ ВО «Национальный исследовательский университет "Московский институт электроники и техники"» и даже ФГБОУ ВО «Московский государственный университет им. М.В. Ломоносова», целесообразно в рамках дальнейшего анализа все вузы и филиалы с такой формулировкой рассматривать как «не выполнившие данный критерий». Кроме того, следует отнести их в ту или иную группу исходя из фрактически выполненного количества критериев, а также исключить из анализа реорганизуемые организации (таблица 7).

Таблица 7 - Распределение учебных заведений ВО по количеству выполненных критериев

\begin{tabular}{|c|c|c|c|c|c|c|c|c|c|}
\hline \multirow{2}{*}{ Образовательное учреждение } & \multicolumn{8}{|c|}{ Количество выполненных критериев } & \multirow{2}{*}{ Bcero } \\
\hline & 0 & 1 & 2 & 3 & 4 & 5 & 6 & 7 & \\
\hline \multicolumn{10}{|c|}{ Мониторинг 2014} \\
\hline Учебные заведения г. Москвы & 4 & 14 & 36 & 41 & 44 & 30 & 19 & 7 & 195 \\
\hline Итого, \% & 2,05 & 7,18 & 18,46 & 21,03 & 22,56 & 15,38 & 9,74 & 3,59 & 100 \\
\hline Учебные заведения Московской области & 3 & 5 & 19 & 33 & 27 & 13 & 10 & 5 & 115 \\
\hline Итого, \% & 2,61 & 4,35 & 16,52 & 28,70 & 23,48 & 11,30 & 8,70 & 4,35 & 100 \\
\hline \multicolumn{10}{|c|}{ Мониторинг 2017} \\
\hline Учебные заведения г. Москвы & 0 & 0 & 8 & 7 & 35 & 61 & 28 & 15 & 154 \\
\hline Итого, \% & 0 & 0 & 5,19 & 4,55 & 22,73 & 39,61 & 18,18 & 9,74 & 100 \\
\hline Учебные заведения Московской области & 0 & 1 & 2 & 5 & 12 & 17 & 16 & 5 & 58 \\
\hline Итого, \% & 0 & 1,72 & 3,45 & 8,62 & 20,69 & 29,31 & 27,59 & 8,62 & 100 \\
\hline
\end{tabular}

Таким образом, за 3-летний период произошел не только существенный рост количества критериев, выполняемых вузами и филиалами. Сам удельный вес образовательных организаций г. Москвы и Московской области, реализовавших по 5 показателей, возрос и достиг 39,61 и $29,31 \%$ соответственно.

При этом, если рассматривать высшие учебные заведения г. Москвы и Московской области как две отдельные статистические совокупности, в них наблюдается симметрия: значения средней величины, моды и медианы совпадают (5 критериев). Коэффициент вариации, отражающий однородность совокупности и являющийся более эффрективным по сравнению с абсолютными показателями вариации, составляет 24,1 и 26,5 \% соответственно для организаций г. Москвы и Московской области [3]. Это существенно отличается от результатов, полученных по Мониторингу 2014. Тогда отмечалась левосторонняя асимметрия для распределения образовательных учреждений г. Москвы и правосторонняя - для вузов и фрилиалов Московской области. Величина коэффициента вариации для вузов и филиалов г. Москвы по Мониторингу 2014 равнялась $438,3 \%$, для Подмосковья $-433,7 \%$.

В результате планомерной деятельности Минобрнауки РФ и самих вузов и филиалов достигнута однородность в составе образовательных учреждений ВО двух регионов России. Это позволяет сделать вывод о наличии одинаковых качественных условий для подготовки специалистов в этих субъектах РФ. 


\section{Ссылки:}

1. Информационно-аналитические материалы по результатам анализа показателей эффеектвности образовательных организаций высшего образования. Приложения к Мониторингу 2013 [Электронный pecypc]. URL: https://miccedu.ru/monitoring/2013/index.htm (дата обращения: 11.11.2017).

2. Информационно-аналитические материалы по результатам анализа показателей эффективности образовательных организаций высшего образования. Мониторинг 2014 [Электронный ресурc]. URL: https://miccedu.ru/monitoring/2014/index.htm (дата обращения: 11.11.2017) ; Информационно-аналитические материалы по результатам анализа показателей эффрективности образовательных организаций высшего образования. Мониторинг 2017 [Электронный ресурc]. URL: http://indicators.miccedu.ru/monitoring/?m=vpo (дата обращения: 11.11.2017).

3. Pearson K. Mathematical contributions to the theory of evolution. III. Regression, heredity, and panmixia // Philosophical Transactions of the Royal Society. Ser. A: Containing Papers of a Mathematical or Physical Character. 1896. Vol. 187. P. 253-318.

\section{References:}

Analytical data on Higher Education Institutions Effectiveness Monitoring. Annexes to Monitoring 2013 2017, viewed 11 November 2017, <https://miccedu.ru/monitoring/2013/index.htm>, (in Russian).

Analytical data on Higher Education Institutions Effectiveness Monitoring. Annexes to Monitoring 2014 2017, viewed 11 November 2017, <https://miccedu.ru/monitoring/2014/index.htm>, (in Russian).

Analytical data on Higher Education Institutions Effectiveness Monitoring. Annexes to Monitoring 2017 2017, viewed 11 November 2017, <http://indicators.miccedu.ru/monitoring/?m=vpo>, (in Russian).

Pearson, K 1896, 'Mathematical contributions to the theory of evolution. III. Regression, heredity, and panmixia', Philosophical Transactions of the Royal Society. Ser. A: Containing Papers of a Mathematical or Physical Character, vol. 187, pp. $253-318$. https://doi.org/10.1098/rsta.1896.0007. 